\title{
GROUP BEHAVIOUR AFFECTS FINANCIAL DECISIONS
}

\author{
Marcelo Henriques de Brito ${ }^{1}$ and Paula Esteban do Valle Jardim ${ }^{2}$ \\ ${ }^{I}$ IBMEC Rio de Janeiro - Centro Universitário IBMEC and Probatus Consultoria Ltda. Brazil \\ ${ }^{2}$ IBMEC Rio de Janeiro - Centro Universitário IBMEC, Brazil
}

\begin{abstract}
This work presents a new approach to behavioral finance with a conceptual contribution by suggesting and discussing with examples a list of group behavioral biases, bringing, hence, an additional outlook on how behavioral biases affect financial decisions. While individual behavioral biases are detected in individuals acting alone, group behavioral biases require the scrutiny of group behavior. Thus, a conceptual contribution of this paper, which may be particularly relevant for institutional investors, is to explain with examples - after research and experience - which are the group behavioral biases and their impact upon financial decisions.
\end{abstract}

\section{KEYWORDS}

Behavioral Finance, Decision-Making, Investment, Portfolio Management, Communication, Institutional Investors

\section{GOAL AND CONTEXT OF THIS WORK}

The goal of this work is to list and discuss group behavioral biases and their impact upon financial decisions, especially those resulting from a collective decision-making process. While individuals alone may decide about their single investments, portfolio management of institutional investors most likely results from teamwork, because an investment portfolio usually comprises several asset classes requiring a diversified stable of skilled investment managers, besides the oversight of an investment committee. Although each manager may manifest specific individual behavioral biases when analyzing, recommending, or deciding on when or how to invest, the aggregate decision of all the managers will influence portfolio evaluation and the group may act with its particular biases. This awareness may be particularly important to institutional investors, whose decisions basically stem from a committee or a group that will exhibit behavioral biases depending on how the group members interact between themselves when making a decision, which may include negotiation activities and not necessarily be related to personality or hierarchy.

\section{A REVIEW ON INDIVIDUAL BEHAVIORAL BIASES}

An understanding of the systems used by humans for judgements and choices is required to address and also to distinguish individual behavioral biases from cognitive errors. Indeed, humans use two systems to judge and choose. Their characteristics are briefly shown in the next page with Table 1, which summarizes content in Kahneman (2011), Thaler and Sunstein (2007), and Statman (2017).

Almost at the end of the description on the differences between "System 1" and "System 2", Kahneman (2011, page 98) explains in that first part of his book "Thinking, fast and slow" that: "the technical definition of heuristics is a simple procedure that helps find adequate, though often imperfect, answers to difficult questions. The word comes from the same root as eureka". This statement focuses on the convenience of having a simple procedure, though often imperfect, to solve problems and to simplify decision-making.

The reason for applying heuristics - also known as 'rules of thumb' - is that "humans have limited time and brainpower", as explained by Thaler (2016, page 22), who also understood that "using these heuristics causes people to make predictable errors". Once the predictable errors are recurrent and not random, a systematic error is introduced into the decision-making process. Therefore, choices will constantly lead to inappropriate outcomes over other possibilities. In other words, heuristics lead to decision biases. 
Table 1. "System 1" and "System 2": systems used by humans for judgements and choices

\begin{tabular}{c|c}
\hline "System 1" & "System 2" \\
\hline intuitive "blink" system & reflective "think" system \\
\hline automatic operations & controlled operations \\
\hline fast & slow \\
\hline effortless and is 'never tired' & effortful and 'gets tired" \\
\hline associative memory & deductive \\
\hline underweights low probabilities & capable of statistically thinking \\
\hline focus only on existing evidence & takes into account absent evidence \\
\hline unconscious process & self-aware \\
\hline underlie intuitive thinking & triggered when intuitive solution does not arrive \\
\hline trained by "System 2" to use simple rules & use of expert solutions \\
\hline
\end{tabular}

Table inspired by content in Kahneman (2011), Thaler and Sunstein (2009), and Statman (2017).

Furthermore, there are different types of heuristics, as pointed out by Ackert and Deaves (2010, page 86) in their book "Behavioral Finance": "Heuristics come in all shapes and sizes. One dichotomy is between those heuristics that are reflexive, autonomic, and noncognitive, and economize on effort (Type 1); and others, which are cognitive in nature (Type 2). Type 1 heuristics are appropriate when a very quick decision must be made or when the stakes are low. ... Type 2 heuristics are more effortful and are appropriate when the stakes are higher. In some cases, an initial reaction using a Type 1 heuristic can be overruled or corroborated using a Type 2 heuristic". From this account and observing Table 1, it is possible to link heuristics Type 1 and Type 2 to "System I" and "System 2" respectively.

If mishaps are not perceived, seen or felt, a 'rule of thumb' may be repeated so often that it becomes a habit. However, the repetition of an inadequate rule of thumb may become a habit without anyone noticing that the habit is the cause of harmful effects, damages, or losses. Furthermore, a habit may be so powerful that the change is difficult and requires effort and techniques, as explained by Duhigg (2014). Scarcity of time, money, and other resources makes the change of a habit even harder, besides threatening the capacity to focus on what is important, as explained by Mullainathan and Shafir (2016).

Biases result from heuristics adopted with such regularity that the heuristics become a habit in such a way that some actions may be unconscious and eventually repeated compulsively. This fact should be of concern to investors and financial practitioners. Indeed, they have the habit of employing several 'rules of thumb' with the belief that the shortcuts are useful. Although the results are not 'perfect', the obtained estimate may be quite close to the actual value. However, some heuristics perhaps should be relinquished.

Behavioral biases may be a consequence from either cognitive errors or emotional biases. The impact of behavioral bias on financial activities has motivated research such as the work "Do Behavioral Biases Affect Prices?" by Coval and Shumway (2005). Their work identifies that "traders are highly loss averse and losing traders actively purchase contracts at higher prices and sell contracts at lower prices than those that prevailed previously. However, price changes as a result of the behavior of loss-averse traders are reversed more quickly than those set by "unbiased" traders". These findings signalize that behavioral bias may affect financial market efficiency, which underlies the importance of understanding how behavioral finance may affect investment decisions and portfolio management.

While emotional biases emanate from intuition, impulse, feelings - i.e. "System l" activities with type 1 heuristics -, cognitive errors emanate from faulty reasoning - i.e. "System 2" activities with type 2 heuristics - , being the latter easier to moderate, reduce or even eliminate than the former. Therefore, emotional biases are biases by way of a "system 1 driven behavior", whereas cognitive errors are errors by means of a "system 2 driven behavior". Individuals may have more or less difficulty to switch on "System 2" and, hence, dismiss "System I". Therefore, emotional biases should be harder to control, change or dismiss than cognitive errors, including those resulting from established, rational and expert heuristics. In his book "The intelligent investor", Benjamin Graham makes the following statement (Graham, 2003, chapter 5, page 21): "The kind of securities to be purchased and the rate of return to be sought depend not on the investor's financial resources but on his financial equipment in terms of knowledge, experience, and temperament". Thus, he does point out that behavior driven by "System 1" ("temperament") and by "System 2" ("experience" with expert heuristics) may be as important as financial knowledge. Work on individual behavioral biases is available in Pompian (2011) and Pompian (2016), as well as other publications on behavior finance. 


\section{GROUP BEHAVIORAL BIASES}

Arnold Wood in an article on "Behavior Finance and Investment Committee Decision Making" clearly writes: "A thorough understanding of the behavioral biases of individuals as they interact in a group, such as a committee, requires that the committee chair proactively neutralize both the behavioral and social obstacles that impede a committee's successful achievement of its goals" (Wood, 2006, page 29). Therefore, both portfolio performance and investment committee effectiveness will most likely depend on both group behavioral biases and individual behavioral biases.

Group behavioral biases are only identified in groups rather than in persons alone. Some members may be able to influence more than others the resulting group behavioral biases due to different reasons, which must be unveiled in order to improve both the efficiency and the quality of group decision-making on financial issues. Pitfalls during the process may not be easily ascribed to a certain group member and his or her cognitive errors or emotional biases. Even a group leader by herself or himself may not necessarily reveal the same bias when making a decision as other group members or even as the group acting as a whole. Actually, a manager may knowingly gather individuals with different biases so that the resulting group exhibits a desired profile. This work suggests that there are two broad types of group behavioral biases with Table 2 .

Table 2. Group Behavioral Biases

\begin{tabular}{|c|c|c|}
\hline group biases related to & $\begin{array}{c}\text { group dynamics biases } \\
\text { (features related to "System 1") }\end{array}$ & $\begin{array}{l}\text { information-acceptance biases } \\
\text { (features related to "System 2") }\end{array}$ \\
\hline group structure & $\begin{array}{c}\text { kin bias (belonging bias) } \\
\text { harmony bias } \\
\text { competition bias }\end{array}$ & $\begin{array}{c}\text { gender bias } \\
\text { survivorship bias } \\
\text { equality bias }\end{array}$ \\
\hline decision-making procedure & $\begin{array}{c}\text { herding } \\
\text { fad bias } \\
\text { Plato bias (denial bias) } \\
\text { scarcity bias } \\
\text { home bias }\end{array}$ & $\begin{array}{l}\text { cohesion bias } \\
\text { analytical bias } \\
\text { momentum bias } \\
\text { halo effect bias } \\
\text { deceit bias }\end{array}$ \\
\hline
\end{tabular}

This table is a contribution of this paper.

The first set assembles group dynamics biases, which depict how a group may act on and react to information in ways that are neither optimal nor suitable and actually may even be harmful to themselves or to others. In these cases, a cohesive group reaches a decision in a dynamic, almost automatic way (likewise "System 1" for individuals alone - see Table 1). The other set assembles information-acceptance biases, which depict how a group may collect, process, and disclose information in a distorted way, albeit employing an effortful process to make a decision (likewise "System 2" for individuals alone - see Table 1). Each broad type of group behavioral biases is subdivided into biases related to the structure of the group and biases related to how the group decision-making procedure occurs.

The description of group dynamics biases begins by addressing biases related to the manner the group is structured. In a kin bias (or belonging bias), the group naturally expect emotional involvement from its members and almost an irrevocable commitment that each one will remain part of the "clan" or "family". The attachment to the group happens at the expense of privacy and individuality. The members lack initiative and blindly obey the leader. These groups have difficulties with debates and creativity. In a group with a harmony $\underline{\text { bias, }}$ members wish to feel comfortable and praise a friendly environment, although there is no obligation of a total attachment, as it is expected in a group with kin bias. Thus, in a group with a harmony bias, there is just an unwillingness to argue, to discuss, and to disagree between group members. The group praises and takes time to form unanimous opinions and strongly and spontaneously discourages dissenting points of view. Precisely the opposite occurs in a group with a competition bias, when there is tough internal competition and great stress during group activities. Normally, the group leader strongly believes that internal competition fosters both efficiency and effectiveness even at expense of eventual gains from collaboration. Such groups tend to have a high turnover of members.

Group dynamics biases may also be sorted according to five different decision-making procedures. Herding is probably the most known and mentioned group bias when explaining "irrational markets". Individuals may just flock together, decide and act in synch, without even understanding the reason to do so or being able to clearly identify a leader. The herding process was studied by Freud (1932) and its occurrence 
in financial markets has been reported by Mackay (1841) in the well-known book "Memoirs of Extraordinary Popular Delusions and the Madness of Crowds" and also by Chancellor (2001), for example.

In a fad bias, a group accepts with great enthusiasm what is new and popular and at the same moment rejects what might be deemed to be outdated or no longer suitable, when it is not. Unlike herding, a group with a fad bias is aware that popularity would guide financial decisions. Thus, fad bias also explains why an investment style or a stock may be out of favor for a brief period of time.

The Plato bias (or denial bias) is related to the Plato's Cave account from the Greek philosopher Plato and refers to the unwillingness of group members to accept and even to have the desire to search for new information. These group members are somehow "chained in their cave" to the information that they currently have. Thus, the Plato bias (or denial bias) has links to the "confirmation bias" of individuals. The Plato bias may have happened with groups of financial analysts covering and praising Enron, when the company was "the only financial institution that cannot produce a balance sheet or cash-flow statement with their earnings", as pointed out at that time by Robert Grubman, a hedge fund manager (apud Mclean and Elkind, 2004, chapter 19, pages 325 to 326).

In a group displaying scarcity bias, the group strives for an efficient use of resources, which does not necessarily imply an effective use. In such cases, the group avoids paying for information, incurring expenses, or dedicating more time to improve their tasks. One consequence is producing simple explanations for causality and correlation. The group may draw conclusions that are incomplete or simply wrong. Mullainathan and Shafir (2016) discuss the effect of scarcity inducing "tunneling", which is an intense focus on just what is immediate or important at the expense of other issues that could be informative or useful.

Home bias denotes a preference for the investments available in the home country. Of course, individuals alone may demonstrate home bias, but actually they will also demonstrate other bias that would explain why they would also exhibit home bias. For example, who has an "illusion of control bias" will likely not invest abroad where control is certainly not possible. The investor would then maintain at home all investments (a "home bias") precisely due to the erroneous belief that a control is possible ("illusion of control bias"). Additionally, "availability bias" and "endowment bias" may be also close related to familiarity with a country, as explained and exemplified by Pompian et al. (2011). If a group is sufficiently diversified, there should always be a member who would understand the advantages of international diversification and who would also know how to invest abroad and the implications of such decisions, including filing and disclosing reports to tax authorities. However, home bias will likely be identified in groups where members tend to have strong patriotic feelings and to praise familiarity (shunning unknown situations), besides not having either the willingness or chance of an international exposure (such as living abroad). They might not even have the idea or drift to seek investment alternatives beyond their own borders. In any case, investing abroad may be challenging, because requires not only knowledge on international finance (including currency management, as explained by Barker, 2013), and ultimately hedging foreign currency exposure, as discussed by Pojarliev (2018), but also a broad comprehension of domestic politics blended with geopolitical issues.

Likewise group dynamics biases in Table 2, information-acceptance biases may also be divided into a set related to how the group is structured and another set related to the decision-making procedure. All these group bias share errors related to collecting, processing, or disclosing information. Normally the group members are conscious about their biases but are either unable or unwilling to change the setting.

Not all groups praise gender diversity as a source of new ideas and creativity. Such groups will have a gender bias, once men and women have a different outlook. Increasingly women are occupying relevant roles and are participating more in balanced groups, but a gender gap still remains, as shown by the research "Gender Diversity in Investment Management" conducted by CFA Institute Research Foundation (2016). More books are being published about how women and men may be complements of each other, such as described by Misner et al. (2012), for example. The movie "Equity" (directed by Meera Menon, 2016) shows how women are contributing to the development of the financial industry.

Equality bias appears when a group strives to treat everybody equally, which is not the same as treating everybody equitably (or fairly). Fairness requires that "equals should be treated equally and unequals unequally", which is a notable principle of justice attributed to the Greek Aristotle. Thus, fairness is overruled when a group ignores differences between members and treats everyone in the same way. The same holds for clients. Additionally, a deep-rooted heuristics is to spread available resources equally among available alternatives, including the "The $1 / N$ rule" (also known as "diversification heuristics"), when allocations to asset classes are equally weighted, regardless of the contribution of each asset class in terms of mean returns, volatility, and correlation (Brunel et al., 2017, section 5). Using data of employee-invested 
defined-contribution (DC) pensions plan using the diversification heuristics, Ackert and Deaves (2010, page 303) discuss the use of "diversification heuristics". This rule of thumb was also personally employed by Harry Markowitz, who admitted being capable of employing such naïve investment procedure for the asset allocation of his retirement account, although he introduced mean-variance optimization (MVO) used in practice to develop and set asset allocation (Zweig, 2007, chapter 1, page 4).

Survivorship bias distorts the assessment of a group when the database reflects only group members with positive, favorable results, because members with negative results are no longer available (i.e. do not "survive") when the assessment occurs. Survivorship bias jeopardizes the assessment of hedge fund performance, when managers with poor records do not remain in the database, because they left business. Survivorship bias is closely related to sample selection bias, when discretionary exclusion of components of a sample may affect the statistical inference when using that sample.

In groups with a cohesion bias, there is an agreement or cooperation to pursue the group's own interests regardless of what third parties desire or ask. The group can help third parties (such as associations providing social work), but may also be united to collude (such as a cartel). This bias is studied by Game Theory.

Groups with analytical bias share the belief that an appropriate solution is only possible and will just be found with the use of theories and tested models, especially quantitative models. Thorough analysis with prudence, diligence and care may not necessarily improve forecasts, and even cause a decision paralysis in a financial choice. Furthermore, persistency to meticulously analyze data may lead to data-snooping bias, when spurious patterns in the database may eventually be found and deemed to be significant, although spurious patterns are misleading and may ruin the final conclusions.

By giving preponderant relevance to historical data, momentum bias is closely related to analytical bias, although differing from fad bias because momentum bias is based on data not on facts. In finance, groups with momentum bias believe that an effective strategy is "trend-following", which has also pitfalls, since there is no perfect strategy. Related to momentum, Statman (2017, chapter 10, page 277) mentions the "frog in the pan" observation that "investors are less attentive to information when it arrives gradually in small bits than to the same information when it arrives instantaneously in one large lump. Continuous information induces momentum as stock prices change gradually". Therefore, a group with a tilt to momentum bias may disregard a flow, which may at first seem irrelevant, but which may ultimately cause damages.

Another information-acceptance bias is the halo effect bias, which consists in making inferences about performance based on overall impressions, given the difficulty to truly identify independent variables affecting performance. Prominent, visible, and external factors, including appearance, may overwhelm the true causes that explain and sustain performance. Rosenzweig (2007) describes the halo effect, which may affect groups engaged in fundamental analysis of corporate securities. Groups with the halo effect bias may not be capable of not letting them be enchanted or seduced by prominent, visible and external factors.

Finally and unfortunately, there are groups organized with the unethical and illegal intent to deceit. Groups with deceit bias believe they may practice to deceive others, obtaining gain at the expense of others, and that they will never get caught. Such groups can be employees in a company and can be the company itself. There are several movies on financial activities in which the plot is based on groups with a deceit bias, such as: Wall Street (Oliver Stone, 1987), Boiler Room (Ben Younger, 2000), The Wolf of Wall Street (Martin Scorsese, 2013) and The Big Short (Adam McKay, 2015). A drawback of such films to the financial industry may be making laypersons believe that deceit is current practice, which is definitely not true.

\section{CONCLUSION}

Biases resulting from groups acting as a whole may indeed be different from individual biases. Although no work was found about groups "thinking fast and slow" with a "System 1" and a "System 2", as shown in Table 1 for individuals, a cohesive group presumably may also reach a decision in a dynamic, almost automatic way (likewise "System 1") or take more time to make a decision (likewise "System 2"). Therefore, Table 2 presents group behavioral biases, which are only identified in groups, rather than in persons by themselves, as discussed in publications on behavior finance. The awareness on how groups organize themselves to make financial decisions may improve both the efficiency and the quality of group decision-making on financial analysis, recommendation, and action. Further research may find other examples and even additional group biases. 


\section{REFERENCES}

Ackert, L. F. and R. Deaves, 2010. Behavioral Finance. South-Western Cengage Learning, USA.

Barker, W.A., 2013. Currency Management: An Introduction. In: The 2019 CFA Program Curriculum Level III, Volume 3, Reading 21, CFA Institute, Charlottesville, USA.

Brunel, J.L.P. et al., 2017. Principles of Asset Allocation. In: The 2019 CFA Program Curriculum Level III, Volume 3 , Reading 19, CFA Institute, Charlottesville, USA.

CFA Institute Research Foundation, 2016. Gender Diversity in Investment Management, research available at https://www.cfainstitute.org/en/research/survey-reports/gender-diversity-report, last access 2 November 2019.

Chancellor, E., 2001. Salve-se Quem Puder [title in English: Devil Take the Hindmost]. Plume, New York.

Coval, J.D. and T. Shumway, 2005. Do Behavioral Biases Affect Prices? In Journal of Finance, Vol. 60, No. 1, (February 2005), pp 1-34.

Duhigg, C., 2014. The Power of Habit. Random House Trade Paperbacks, New York, USA.

Freud, S., 1932. Massenpsychologie und Ich-Analyse. In: Studienausgabe-Band IX-Fragen der Gesellschaft Ursprünge der Religion, S.Fischer Verlag, 1974, Frankfurt am Main, Germany.

Graham, B., 2003. The Intelligent Investor: a book of practical counsel. Revised edition. Updated with new commentary by Jason Zweig and with Preface and Appendix by Warren Buffett. HarperCollins Publishers, New York, USA.

Kahneman, D., 2011. Thinking, fast and slow. Farrar, Straus and Giroux, New York, USA.

Lo, A. W., 2017. Adaptive Markets. Princeton University Press, New Jersey, USA.

Mackay, Ch., 1841. Extraordinary Popular Delusions and the Madness of Crowds. Start Publishing LLC. Kindle, 2012.

Mclean, B and P. Elkind, 2004. The smartest guys in the room: The amazing rise and scandalous fall of Enron, Penguin Books, London, UK.

Misner, I. et al., 2012. Essa Ideia É Tão Boa Que Parece Que Foi Sua: como usar as diferenças entre homens e mulheres para convencer nos negócios [title in English: Business Networking and Sex]. Universo dos Livros, São Paulo, Brazil

Mullainathan, S. and E. Shafir, 2016. Escassez [title in English: Scarcity]. Best Business, Rio de Janeiro, Brazil.

Pojarliev, M., 2018. Some Like It Hedged. In: CFA Institute Research Foundation Books, 7 November 2018, Volume 4, Issue 6, CFA Institute, Charlottesville, USA.

Pompian, M.M., 2011.The Behavioral Biases of Individuals. In: The 2019 CFA Program Curriculum Level III, Volume 2, Reading 8, CFA Institute, Charlottesville, USA.

Pompian, M.M., McLean, C. and A. Byrne, 2011. Behavioral Finance and Investment Processes. In: The 2019 CFA Program Curriculum Level III, Volume 2, Reading 9, CFA Institute, Charlottesville, USA.

Pompian, M., 2016. Risk Profiling through a Behavioral Finance Lens, CFA Research Foundation Briefs, available at https://www.cfainstitute.org/en/research/foundation/2016/risk-profiling-through-a-behavioral-finance-lens, last access 2 November 2019.

Rosenzweig, Ph.M., 2007. The Halo Effect. Free Press, New York, USA.

Statman, M., 2017. Finance for Normal People. Oxford University Press, New York, USA.

Thaler, R.H., 2016. Misbehaving: the making of behavioural economics. Penguin Random House, UK.

Thaler, R.H. and C.R. Sunstein, 2009. Nudge. Penguin Books, New York, USA.

Wood, A. S., 2006. Behavioral Finance and Investment Committee Decision Making. In: CFA Institute Conference Proceedings Quarterly, (December 2006), pp 29-36.

Zweig, J., 2007. Your Money and Your Brain. Simon \& Schuster Paperbacks, New York, USA. 